\title{
Paternal environmental exposure-induced spermatozoal small noncoding RNA alteration meditates the intergenerational epigenetic inheritance of multiple diseases
}

Xin Yin, Azhar Anwar, Yanbo Wang, Huanhuan Hu, Gaoli Liang, Chenyu Zhang (ه)

Nanjing Drum Tower Hospital Center of Molecular Diagnostic and Therapy, State Key Laboratory of Pharmaceutical Biotechnology and Department of Physiology, Jiangsu Engineering Research Center for MicroRNA Biology and Biotechnology, NJU Advanced Institute of Life Sciences (NAILS), School of Life Sciences, Nanjing University, Nanjing 210023, China

(C) The Author(s) 2021. This article is published with open access at link.springer.com and journal.hep.com.cn

\begin{abstract}
Studies of human and mammalian have revealed that environmental exposure can affect paternal health conditions as well as those of the offspring. However, studies that explore the mechanisms that meditate this transmission are rare. Recently, small noncoding RNAs (sncRNAs) in sperm have seemed crucial to this transmission due to their alteration in sperm in response to environmental exposure, and the methodology of microinjection of isolated total RNA or sncRNAs or synthetically identified sncRNAs gradually lifted the veil of sncRNA regulation during intergenerational inheritance along the male line. Hence, by reviewing relevant literature, this study intends to answer the following research concepts: (1) paternal environmental factors that can be passed on to offspring and are attributed to spermatozoal sncRNAs, (2) potential role of paternal spermatozoal sncRNAs during the intergenerational inheritance process, and (3) the potential mechanism by which spermatozoal sncRNAs meditate intergenerational inheritance. In summary, increased attention highlights the hidden wonder of spermatozoal sncRNAs during intergenerational inheritance. Therefore, in the future, more studies should focus on the origin of RNA alteration, the target of RNA regulation, and how sncRNA regulation during embryonic development can be sustained even in adult offspring.
\end{abstract}

Keywords small noncoding RNAs; epigenetic inheritance; paternal intergenerational inherence; extracellular vesicles

\section{Introduction}

Parental environmental exposure can induce phenotype changes and lead to the passing on of a specific phenotype to offspring. This phenomenon may contribute to explaining some heritable diseases, such as modern lifestylecaused obesity, type 2 diabetes mellitus, and mental illness, that cannot be fully understood in a classical DNA sequence-based heritable manner. These findings support the theory of Lamarck, who proposed "inheritance of acquired characters" from their parents [1]. Moreover, paternal factors play an important role, and studies have mainly focused on sperm cells [2,3]. However, the molecular mechanism of the transmission of paternal factors to offspring remains unknown. Many studies have

Received April 10, 2021; accepted July 30, 2021

Correspondence: Chenyu Zhang, cyzhang@nju.edu.cn proposed potential epigenetic mechanisms, such as DNA methylation, histone modification, and small noncoding RNAs (sncRNAs), in germ cells (sperm and eggs) [4].

Recent studies have shown that different classes of sncRNAs, including microRNAs (miRNAs), piRNAs (piwi-interacting RNAs), tRNA-derived small RNAs (tsRNAs), and rRNA-derived small RNAs (rsRNAs), in sperm exhibit alterations when exposed to environmental stress, such as diet (high-fat diets and low-protein diets) [5], mental stress [6,7], and metabolic disorders [8-10]. Moreover, injection of isolated total RNA or sncRNAs from paternal sperm into wild-type zygotes provides direct evidence to demonstrate the important epigenetic effects of sperm sncRNAs during intergenerational transmission of paternal-acquired phenotype processes [6-9].

sncRNAs mediating paternal intergenerational inheritance are still in the early stages of development, but a considerable amount of academic research has accumulated in this field. Here, we review the current literature on 
paternal intergenerational inheritance phenomenon addressing the following issues: description of the paternal intergenerational inheritance phenomenon (focusing on paternal metabolic stress and mental stress); sperm sncRNA variation and their potential role in mediating paternal intergenerational inheritance; the potential mechanism of sncRNA meditation on paternal intergenerational inheritance.

\section{Paternal factors can be passed on to the offspring}

\section{Human clinical trials}

More evidence suggests that the transgenerational response results from parental environmental exposure. Human trials are limited because distinguishing genetic, epigenetic, and cultural influences during transgenerational processes is crucial [11]. However, several human studies justify the actual existence of transgenerational effects. In 2007, Lumey et al. [12] found that parental malnutrition was associated with metabolic diseases in children in epidemiological studies of the Dutch Hunger Winter of 1944-1945. This study provides indirect evidence that abnormal conditions, such as starvation during maternal pregnancy may cause inaccurate importing of information during the embryonic development of offspring. Illuminating the transgenerational effects is difficult given the complications of maternal pregnancy. Therefore, several human studies emphasizing paternal effects on offspring can better explain the transgenerational effects, and clues from paternal environmental exposure are obtained, leading to many rodent studies that have recently focused on alterations in sperm cells.

Bygren et al. [13] first found a connection between the availability of food for paternal ancestors in mid-childhood and the longevity of grandchildren based on detailed historical records of harvests on the Överkalix cohort in Northern Sweden in 1905. More precisely, the arresting intergenerational effects revealed that paternal grandfathers' good food availability was associated with a shorter lifespan for the grandchild, and poor availability imparted a longer life [14]. Subsequently, the same group further analyzed the data and revealed that food availability in the paternal grandfathers' mid-childhood was associated with mortality due to cardiovascular disease and diabetes of the proband. Paternal grandfathers' sufficient food supplementation increased cardiovascular and diabetes mortality of the proband [15]. Interestingly, in 2006, Pembrey et al. [16] found that Swedish data actually showed a sex-specific pattern. The food supply of paternal grandfathers and maternal grandmothers only affects the mortality of their grandsons and granddaughters, respectively. This series of studies provided indirect evidence for transgenerational effects. Several studies have been performed to test the hypothesis of transgenerational effects. Chen et al. [17] demonstrated that paternal betelquid chewing increased the risk of early manifestation of metabolic syndrome in human offspring in a dosedependent manner based on a community-integrated screening program in Taiwan region. Northstone et al. [18] reported that smoking by paternal mid childhood may contribute to obesity in adolescent male offspring using the Avon Longitudinal Study of Parents and Children (ALSPAC). A recently published paper in Nature Communications by Denny et al. [11] expanded the data set almost 40 times to explain the association between the food supply of grandfathers $(n=9039)$ and the mortality of children $(n=7280)$ and grandchildren $(n=11561)$. Indeed, paternal grandfathers' food supply in prepuberty predicts his male, but not female, grandchildren's all-cause mortality. However, only cancer mortality follows this pattern, and no diabetes or cardiovascular mortality has been reported.

Referring to the intergenerational transmission of mental stress, several human studies have demonstrated that paternal mental stress can impact the mental health of offspring. For example, cohort studies of Holocaust survivors and their offspring reported an enhanced prevalence of neuropsychiatric disorder, posttraumatic stress disorder (PTSD), reduced cortisol levels, and glucocorticoid receptors (GR) [19]. Other environmental variations, such as toxicants and smoking, have also been reported to affect human paternal sperm [20,21].

In summary, because few human trials have been conducted to study the paternal transgenerational effect, the existence of paternal transgenerational effects can be confirmed. However, the mechanisms of biological events between cells, especially somatic and sperm cells, remain unclear. More research that focuses on rodents is required to clarify this issue.

\section{Animal trials}

The term "epigenetics" was first proposed by Waddington Hull to explain the "crossveinless" phenotype [22]. In 1953 , Waddington heated the pupae of flies to $40{ }^{\circ} \mathrm{C}$ to cause a phenotype of a break in the transverse veins of the wing. After several generations of selection, the most significant break in the vein was selected and subsequently stored at normal temperature subsequently. Astoundingly, the crossveinless phenotype still existed in the selected fly offspring. This evidence was the first of advanced epigenetic inheritance research, even though it was not recognized at that time. Currently, epigenetic phenomena are characterized as "gene expression changes that are mutation independent and heritable in the absence of the triggering event [23]." In 1994, Boucher et al. [24] first observed the intergenerational inheritance phonotype in 
mice when they focused on betel nut consumption-induced metabolic disorder and found that paternal betel nut consumption is related to the metabolic disorder of their offspring rather than the simple effect of maternal hyperglycemia during gestation. This research was consistent with the human trial of paternal betel-quid chewinginduced metabolic disorder in the offspring mentioned [17].

More recently, a series of studies in the white tail of mice [25], C. elegans longevity [26,27], metabolic disorder in mice [8-10,24], mental stress [6,7,28-30], mental stress induced metabolic disorder in offspring [31], and chemical exposure $[20,32,33]$ supports the theory of "intergenerational inheritance" along the male line. The role of sncRNAs in these non-Mendelian inheritance phenotypes will be discussed subsequently in the manuscript.

Combined with clinical and animal trials, intergenerational inheritance is greatly interesting to genetics, and the molecular mechanism appears to be very important to explain this non-Mendelian inheritance phenotype.

\section{Ideal "RNA-mediated epigenetic inheritance"}

The idea of "RNA-mediated epigenetic inheritance" was first proposed by Rassoulzadegan's group in their research on the Kit gene mutant-induced white tail phenotype, the first mouse model of epigenetic inheritance described as paramutation of the Kit gene [25]. They found that the mutation abrogates the synthesis of the Kit tyrosine kinase receptor, which is critical in several developmental processes, including germ cell differentiation, hematopoiesis, and melanogenesis. The homozygotes died shortly after birth, and the heterozygotes showed a white tail tip and feet phenotype. Interestingly, the offspring of Kit heterozygotes mice also showed white tail tip and feet phenotype in heterozygote Kit mutant mice and homozygote wild-type mice when they mated with Kit heterozygotes mice. In these pups, the expression of the Kit gene was also reduced despite the presence of normal alleles. Furthermore, they injected isolated total RNA from heterozygous Kit mutant mouse sperm cells, and miR-221/ 222 specifically targeted the Kit gene and led to the same phenotype. Subsequently, Rassoulzadegan's group further focused on hereditary cardiac hypertrophy with signs typical of human hypertrophic cardiomyopathy (HCM) in response to microinjection of miR-1* (predicted to target $C d k 9$ ) in early embryos (one-cell embryo). However, $C d k 9$, a key regulator of cardiac growth, was upregulated (at mRNA and protein levels) in response to the injection of fragments of either the coding region of $C d k 9$ or miR$1^{*}$, and mice inhibited cardiac hypertrophy [34]. Subsequently, Rassoulzadegan's group moved forward to generate an alternative phenotype for this research area with a giant phenotype. They demonstrated that microinjection of miR-124 into fertilized eggs resulted in a $30 \%$ increase in size from blastocyst to adult and subsequently inherited over several generations either male or female. In addition, they generated miR-124 transgenic male mice during spermatogenesis to further confirm the role of sperm RNA as a transgenerational signal in the giant phenotype of the offspring. Similar to the $C d k 9$ expression pattern, the injection of miR-124 or miR-124 transgenic mice resulted in elevated Sox 9 levels and giant sizes [35].

This finding is puzzling because miRNAs function as negative regulators of target genes. However, in these cases, the injection of specific miRNAs into one-cell embryos resulted in the opposite outcome. These results suggest that sncRNA-mediated epigenetic inheritance does not simply bind to target genes at the transcriptional level but works in an epigenetic method that targets heritable silencing, including the regulation of DNA methylation or histone modification [36], which is still unclear. This series of works spawned the following studies focusing on sncRNA-mediated intergenerational inheritance to determine the potential mechanism and explain this special nonMendelian inheritance phenomenon.

\section{RNA-mediated epigenetic inheritance of C. elegans longevity}

In combination with the Kit gene paramutation study, another study with respect to C. elegans longevity is also crucial to this research field. Greer et al. also observed a similar paramutation phenotype. They first demonstrated the extension of the lifespan of C. elegans after deletion of any histone methylation $\mathrm{H} 3 \mathrm{~K} 4 \mathrm{me} 3$ consisting of three proteins, namely, ASH-2, SDR-5, and SET-2 [26]. Then, they crossed the wild-type male mutant hermaphrodites with knockout for the $w d r-5$ gene $(w d r-5 / w d r-5)$ or with mutant hermaphrodites with knockout for set-2 (set-2/set2). After self-fertilization, they detected a $20 \%$ and $30 \%$ increase in longevity in homozygous wild-type hermaphrodites born to heterozygotes $(+/ w d r-5)$ and $(+/$ set- 2$)$, and this extension existed for at least one generation. They adopted an RNAi methodology to study the epigenetic inheritance of the $A S H-2$ gene. They fed wild-type nematode bacteria expressing siRNA that targeted the $A S H-2$ gene. The mRNA and protein levels of $A S H-2$ were downregulated in parent worms and subsequently extended life. Interestingly, the offspring showed increased longevity in the F1, F2, and F3 generations without ash-2 gene variation compared with norms [27]. The knockout animals and RNAi interference model suggest a similar pattern of epigenetic inheritance to the Kit paramutation model. In summary, the concept of RNA-mediated intergenerational epigenetic inheritance in mammals seems to be of great value in explaining many intergenerational 
inheritances of diseases that cannot be explained by classic genetics.

\section{RNA-mediated epigenetic inheritance of metabolic disorder}

Clinical trials concerning paternal diet conditions that regulate the mortality and metabolic conditions of the offspring trigger off laboratory studies to explore the underlying mechanism of intergenerational epigenetic inheritance. A series of studies revealed that paternal metabolic conditions can pass on to offspring along the male line. Recently, injection of total RNA or sncRNA fragments from sperm has raised great attention because sncRNAs may play an important role during the inheritance of paternal environmental exposure.

Rando's group [37] first applied a low-protein diet in fathers to test whether transgenerational inheritance of environmental information occurs in mammals by measuring the transcriptome of offspring livers. They explained that a paternal low-protein diet elevated the hepatic transcriptome and decreased the levels of cholesterol esters compared with male offspring fed a control diet. Furthermore, their results showed that several miRNAs in offspring livers changed in response to paternal diet. Although they did not measure the level or modification of sncRNAs in sperm, they addressed the potential role of sncRNAs in this transmission. Fullston et al. [38] showed that paternal obesity-induced metabolic disorder of offspring is associated with sncRNA (mainly focused on miRNAs) profiles in testes and sperm. Subsequently, Rassoulzadegan's group [10] provided more direct evidence to reinforce this connection. They also found the inheritance of metabolic disorders along the male line. They pioneered an applied microinjection of either testis or sperm RNA of male fed on a Western-like diet into early one-cell embryo to finally induce metabolic disorder phenotype in the resulting progenies compared with RNAs from healthy controls. Moreover, even the injection of a single miRNA (miR-19) partially reproduced the metabolic phenotype. Although microinjection technology was not novel at that time, this study is the first to demonstrate the potential mediation of sncRNAs in metabolic disorders during transgenerational inheritance.

Another important study conducted by Chen et al. [8] focused more on the regulation of tsRNA (30-40 nt) alteration and modification of tsRNAs in sperm, given that tsRNAs are the most abundant class of RNAs in mature spermatozoa [39]. They applied a high-fat diet to fathers, thereby resulting in insulin resistance in their offspring. Furthermore, they injected the sperm head into normal oocytes, demonstrating the irreplaceable role of paternal sperm. Then, they found modification in sperm tsRNAs and microinjection of isolated tsRNAs or synthetic tsRNAs and provided more direct evidence that the high-fat diet induced modification of sperm tsRNAs is critical for successful transmission but not miRNAs, long RNA fraction, or synthetic oligonucleotides in this case [8]. Subsequently, Rando's group further revealed the biogenesis and function of tsRNAs during sperm maturation and fertilization in mammals. They proposed that these tsRNAs may be shuttled from the epididymis to sperm via epididymosomes (exosomes excreted from the epididymis that are located in the intraluminal epididymal compartment), as small RNAs found in purified epididymosomes closely mirror $(r=0.96)$ those in cauda sperm [9]. Moreover, miRNAs, piRNAs, and proteins are found in epididymosomes [40-42]. Although the idea of sncRNAs shuttled from the epididymis to sperm via epididymosomes is intriguing, more functional experiments are required to demonstrate the exact mechanism of small RNA changes in sperm during environmental exposure.

Studies have shown that abnormal paternal metabolic conditions can affect miRNA and tsRNA levels in sperm cells. Intriguingly, rsRNAs, a class of rRNA-derived small RNAs that were reported to be related to sperm quality biomarkers for in vitro fertilization [43], have also been found to be altered in mature sperm after paternal metabolic disorder [44,45]. Moreover, the phenotypic outcome of injecting 30-40 nt fractions could be a combinatorial effect from tsRNAs and rsRNAs because newly published data have shown that rsRNAs are more abundant in 30-40 nt RNA fractions from mature sperm [46]. These results suggest that rsRNAs are also a potential carrier of epigenetic information in sperm.

Rassoulzadegan's group previously demonstrated that RNA methyltransferase Dnmt2 is required for transmission from father to offspring in their well-established model (Kit paramutation and Sox9 gigantism) [47]. Following this idea, Chen et al. applied Dnmt2 knockout mice and found that the paternal metabolic disorder phenotype could not pass on to their offspring with deletion of Dnmt2. In addition, injections of 30-40 nt sperm RNAs (which are enriched for tsRNAs) reproduced the transgenerational effects in wild-type mice but not in Dnmt2 knockouts [44]. More recently, in 2019, Sarker et al. [48] demonstrated that maternal high-fat diet-induced enhanced metabolic disorders (mainly hedonic behavior and obesogenic phenotypes) were converted across three generations along with the paternal lineage and F1 sperm tsRNAs partly contributed to this transmission and excluded the larger sperm RNA fractions (40-90 nt). Furthermore, they only observed moderate changes in F1 and F2 sperm $\mathrm{CpG}$ methylation, indicating that the sperm methylome may not be responsible for this transmission type, contrary to sncRNAs [49,50]. This finding is also supported by early nutritional animal models [51,52].

In summary, a series of paternal metabolic condition studies provides several ideal transgenerational inheritance 
models of mammals for transgenerational effect research. This finding indicates that sncRNAs may play a crucial role in mediating epigenetic effects along with spermatogenesis and embryonic development.

\section{RNA-mediated epigenetic inheritance of mental stress}

Recently, mRNA and sncRNA populations have been found in human and mouse sperm, suggesting the potential role of sncRNAs in spermatogenesis and embryonic development [53-55]. Dietz et al. [56] applied the chronic social defeat stress paradigm to adult male mice and bred them with normal female mice to generate offspring. They showed that male and female offspring from stressed fathers exhibit increased measures of several depressionand anxiety-like behavior, indicating the epigenetic inheritance of mental stress. Subsequently, Rodgers et al. [57] demonstrated that paternal chronic stress before breeding contributes to offspring hypothalamic-pituitaryadrenal (HPA) axis dysregulation. Offspring from the paternal stress group displayed significantly reduced HPA stress axis responsivity. More importantly, they found significant changes in nine miRNAs in sperm from stress fathers, indicating the potential epigenetic inheritance pathway through miRNA regulation during spermatogenesis and embryonic development. Their findings suggest the important role of RNA in meditating epigenetic inheritance of paternal mental stress and elicit more studies to clarify the idea of RNA-mediated epigenetic inheritance of mental stress.

Gapp et al. [7] initially explored whether environmental stress can induce germline epigenetic inheritance via sperm RNAs. They applied traumatic stress early in the life of mice that changed miRNA expression and behavioral response in offspring. In particular, they injected sperm RNAs from stressed fathers into fertilized wild-type oocytes, resulting in a behavioral response similar to normal breeding. Early-life trauma can damage cognitive function and alter synaptic plasticity in stressed fathers and offspring [58]. Environmental enrichment, a physiologically and socially stimulating environment, could potentially reverse or prevent the stressed effects in the progeny [59]. At that time, environmental enrichment was not linked to sperm RNAs. Benito et al. [29] found that environmental enrichment exposure improved cognitive function and enhanced synaptic plasticity in fathers and offspring. More importantly, they demonstrated that the intergenerational inheritance is mediated by sperm RNA and especially miR-212/132 by injection of isolated sperm RNAs or synthetic RNAs into normal zygotes. A similar improved paternal cognitive function phenotype induced through moderate exercise also passed on to their offspring along male line. Some genes that were predicted as targets of miR-212/132 were enriched and have proven to be key regulators of cognitive improvement [60]. Similarly, Rodgers et al. [6] further found that injection of nine identified miRNA compounds into normal zygotes induced blunted HPA axis activation in the offspring and reduced several mRNA levels in the zygote. Recently, Wang et al. [61] published their work that suggested that offspring born to a paternal depression-like model are susceptible to depression-like symptoms at the molecular, neuronal, and behavioral levels. The levels of sperm miRNAs exhibit distinct expression patterns in a paternal depression-like model. Neutralization of the abnormal miRNAs in zygotes by antisense strands rescues the depression-like phenotype in offspring born to a paternal depression-like model. This finding suggests a potential therapeutic direction for depression-like symptoms. Moreover, their data revealed that the profiles of piRNAs and rsRNAs were altered in paternal depression-like models, whereas the level of tsRNAs remained unchanged. The authors mainly focused on miRNA alteration; however, piRNAs and rsRNAs, which may also confer depression susceptibility to offspring, could be a novel direction for the future work.

More interestingly, Chen's group demonstrated that sncRNAs meditate intergenerational inheritance only partially because isolated sperm sncRNAs from high-fat fathers cannot replicate metabolic disorders on Dnmt2 knockout mice [44]. Gapp et al. recently published further work and found that the intergenerational inheritance of paternal early life trauma can be mediated partly through long RNAs (>200 nt) and partly through small RNAs. Moreover, different types of RNAs seem to meditate different intergenerational inheritance effects because they can reproduce only some of the stress on the anxietyrelated phenotype by injecting isolated sperm total RNAs but not small nor long RNAs [62].

These findings emphasize the important role of different types of sperm RNA and provide a feasible direction to investigate the mechanism of the transmission of environmental mental stress from fathers to offspring. A newly published paper by Bale et al. [63] demonstrated a novel direction to explore the potential mechanism. An apparent phenomenon is that paternal stress can affect offspring phenotype; thus, they collected extracellular vesicles (EVs) from stress-treated epididymal epithelial cells, which were called epididymosomes in previous studies [9,41]. Surprisingly, paternal stress altered protein and miRNA content in stress treated epididymosomes, and they proposed that the secretion of these epididymosomes could affect sperm maturation and may also play a role in stress-induced intergenerational inheritance. This research provides a new direction to understand the transfer of environmental stress information molecules into the reproductive system. However, more functional experiments are required to clarify the mechanism behind this argument. 


\section{Discussion}

The two main hypotheses of Lamarck's theory to explain the gradual complication of organisms in the evolutionary process - the so-called "principle of graduation"- are as follows: inheritance by the body of characteristics acquired throughout life and the presence of a certain internal "striving for perfection." Lamarck explained this phenomenon by his theory of fluids. Advances in modern biology have revealed the possibility of communication between somatic and germ cells in which sncRNAs are packaged into EVs, such as exosomes, to establish cell-cell communication [59]. More importantly, paternal environmental exposure could change the levels of sncRNAs (tsRNAs, piRNAs, miRNAs, and rsRNAs) and may transmit paternal environmental exposure information to offspring by targeting some critical genes during spermatogenesis and subsequent embryonic development would provide an important direction for researchers [6,64]. More research focusing on EVs and their cargo, especially sncRNAs, in the male reproductive system would be significant to the field (Fig. 1).

Current literature has demonstrated that alterations in spermatozoal sncRNAs may play a role in intergenerational inheritance and seminal plasma. However, these alterations have not been investigated. Seminal plasma is the only medium in which exosomal sncRNAs released from somatic cells can pass the reproductive barrier into germ cells. Bale's group demonstrated the vital role of epididymosomes and their cargo, such as sncRNAs; they did not explore the alterations or the role of EVs in seminal plasma. Chen et al. [65] found that alterations in piRNAs in seminal plasma from male humans can serve as molecular biomarkers for male infertility, indicating the vital role of sncRNAs in seminal plasma. However, the limited volume of seminal plasma from male mice increases the difficulty of collection as well as further analysis. Moreover, seminal plasma is vital to the fertilization process. In summary, seminal plasma, which has not been investigated during intergenerational inheritance of acquired characteristics, should be explored in the future.

In addition, because sncRNA levels are very low in one signal sperm and diluted post fertilization, the effect of low-concentration sncRNAs on embryonic development until adulthood is unknown. Several studies have proposed possible mechanisms, such as targeting the maternal mRNA population [6], inducing transcriptional activation or repression within the nucleus through other epigenetic mechanisms [66], and regulating de novo methylation in embryonic stem cells [67]. Evidently, sncRNA regulation acts during fertilization and may regulate nuclear fusion or early fertilized egg development. More studies are required to explore the mechanisms of how sncRNAs regulate this process to clarify the idea of RNA-mediated intergenerational inheritance of paternal acquired characteristics.

In summary, further work that focuses on sperm cells is essential. How somatic cells transfer information to germ cells is also significant because the alteration in sperm cells simplifies the result, but the phenotypic changes in specific organs cause this condition. In addition, the transmitter of seminal plasma should not be ignored because it may also support and complement the integrity of the Lamarck theory. Lastly, the mechanism by which a small number of sncRNAs regulate such precise inheritance processes is unknown.

\section{Conclusions}

Paternal environmental exposure alters the levels of sncRNAs in sperm and increases the risk of diseases in offspring. Normalizing the level of small RNA in sperm by various approaches may be effective in preventing offspring disease.

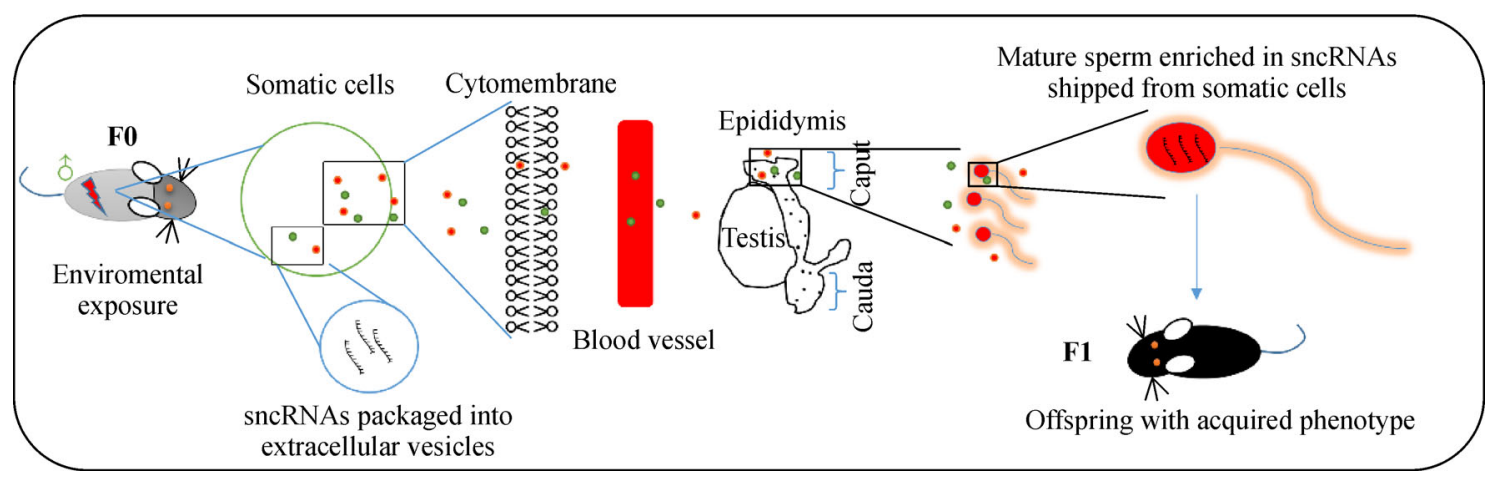

Fig. 1 Schematic of the potential mechanism of how environmental stress information molecules are transferred into the male reproductive system via extracellular vesicles. 


\section{Acknowledgements}

We appreciate the article retrieval service provided by Nanjing University Library.

\section{Compliance with ethics guidelines}

Xin Yin, Azhar Anwar, Yanbo Wang, Huanhuan Hu, Gaoli Liang, and Chenyu Zhang declare that they have no conflict of interest. This manuscript is a review article and does not involve a research protocol requiring approval by the relevant institutional review board or ethics committee.

Open Access This article is licensed under a Creative Commons Attribution 4.0 International License, which permits use, sharing, adaptation, distribution and reproduction in any medium or format, as long as you give appropriate credit to the original author(s) and the source, provide a link to the Creative Commons license, and indicate if changes were made.

The images or other third party material in this article are included in the article's Creative Commons license, unless indicated otherwise in a credit line to the material. If material is not included in the article's Creative Commons license and your intended use is not permitted by statutory regulation or exceeds the permitted use, you will need to obtain permission directly from the copyright holder.

To view a copy of this license, visit https://creativecommons.org/ licenses/by/4.0/.

\section{References}

1. Zhang Y, Shi J, Rassoulzadegan M, Tuorto F, Chen Q. Sperm RNA code programmes the metabolic health of offspring. Nat Rev Endocrinol 2019; 15(8): 489-498

2. Rando OJ. Intergenerational transfer of epigenetic information in sperm. Cold Spring Harb Perspect Med 2016; 6(5): a022988

3. Weigmann K. Lifestyle in the sperm: there is growing evidence that epigenetic marks can be inherited. But what is the nature of the information they store and over how many generations do they prevail? EMBO Rep 2014; 15(12): 1233-1237

4. Sales VM, Ferguson-Smith AC, Patti ME. Epigenetic mechanisms of transmission of metabolic disease across generations. Cell Metab 2017; 25(3): 559-571

5. Klastrup LK, Bak ST, Nielsen AL. The influence of paternal diet on sncRNA-mediated epigenetic inheritance. Mol Genet Genomics 2019; 294(1): 1-11

6. Rodgers AB, Morgan CP, Leu NA, Bale TL. Transgenerational epigenetic programming via sperm microRNA recapitulates effects of paternal stress. Proc Natl Acad Sci USA 2015; 112(44): 13699 13704

7. Gapp K, Jawaid A, Sarkies P, Bohacek J, Pelczar P, Prados J, Farinelli L, Miska E, Mansuy IM. Implication of sperm RNAs in transgenerational inheritance of the effects of early trauma in mice. Nat Neurosci 2014; 17(5): 667-669
8. Chen Q, Yan M, Cao Z, Li X, Zhang Y, Shi J, Feng GH, Peng H, Zhang X, Zhang Y, Qian J, Duan E, Zhai Q, Zhou Q. Sperm tsRNAs contribute to intergenerational inheritance of an acquired metabolic disorder. Science 2016; 351(6271): 397-400

9. Sharma U, Conine CC, Shea JM, Boskovic A, Derr AG, Bing XY, Belleannee C, Kucukural A, Serra RW, Sun F, Song L, Carone BR, Ricci EP, Li XZ, Fauquier L, Moore MJ, Sullivan R, Mello CC, Garber M, Rando OJ. Biogenesis and function of tRNA fragments during sperm maturation and fertilization in mammals. Science 2016; 351(6271): 391-396

10. Grandjean V, Fourré S, De Abreu DA, Derieppe MA, Remy JJ, Rassoulzadegan M. RNA-mediated paternal heredity of dietinduced obesity and metabolic disorders. Sci Rep 2016; 5: 18193

11. Vågerö D, Pinger PR, Aronsson V, van den Berg GJ. Paternal grandfather's access to food predicts all-cause and cancer mortality in grandsons. Nat Commun 2018; 9(1): 5124

12. Lumey LH, Stein AD, Kahn HS, van der Pal-de Bruin KM, Blauw GJ, Zybert PA, Susser ES. Cohort profile: the Dutch Hunger Winter families study. Int J Epidemiol 2007; 36(6): 1196-1204

13. Bygren LO, Kaati G, Edvinsson S. Longevity determined by paternal ancestors' nutrition during their slow growth period. Acta Biotheor 2001; 49(1): 53-59

14. Pembrey ME. Male-line transgenerational responses in humans. Hum Fertil (Camb) 2010; 13(4): 268-271

15. Kaati G, Bygren LO, Edvinsson S. Cardiovascular and diabetes mortality determined by nutrition during parents' and grandparents' slow growth period. Eur J Hum Genet 2002; 10(11): 682-688

16. Pembrey ME, Bygren LO, Kaati G, Edvinsson S, Northstone K, Sjöström M, Golding JA; LSPAC Study Team. Sex-specific, maleline transgenerational responses in humans. Eur J Hum Genet 2006; 14(2): 159-166

17. Chen TH, Chiu YH, Boucher BJ. Transgenerational effects of betelquid chewing on the development of the metabolic syndrome in the Keelung Community-based Integrated Screening Program. Am J Clin Nutr 2006; 83(3): 688-692

18. Northstone K, Golding J, Davey Smith G, Miller LL, Pembrey M. Prepubertal start of father's smoking and increased body fat in his sons: further characterisation of paternal transgenerational responses. Eur J Hum Genet 2014; 22(12): 1382-1386

19. Yehuda R, Daskalakis NP, Lehrner A, Desarnaud F, Bader HN, Makotkine I, Flory JD, Bierer LM, Meaney MJ. Influences of maternal and paternal PTSD on epigenetic regulation of the glucocorticoid receptor gene in Holocaust survivor offspring. Am J Psychiatry 2014; 171(8): 872-880

20. Marczylo EL, Amoako AA, Konje JC, Gant TW, Marczylo TH. Smoking induces differential miRNA expression in human spermatozoa: a potential transgenerational epigenetic concern? Epigenetics 2012; 7(5): 432-439

21. Delbès G, Hales BF, Robaire B. Toxicants and human sperm chromatin integrity. Mol Hum Reprod 2010; 16(1): 14-22

22. Ruden DM, Garfinkel MD, Sollars VE, Lu X. Waddington's widget: Hsp90 and the inheritance of acquired characters. Semin Cell Dev Biol 2003; 14(5): 301-310

23. Ptashne M. Epigenetics: core misconcept. Proc Natl Acad Sci USA 2013; 110(18): 7101-7103

24. Boucher BJ, Ewen SW, Stowers JM. Betel nut (Areca catechu) consumption and the induction of glucose intolerance in adult CD1 
mice and in their F1 and F2 offspring. Diabetologia 1994; 37(1): 4955

25. Rassoulzadegan M, Grandjean V, Gounon P, Vincent S, Gillot I, Cuzin F. RNA-mediated non-mendelian inheritance of an epigenetic change in the mouse. Nature 2006; 441(7092): 469-474

26. Greer EL, Maures TJ, Hauswirth AG, Green EM, Leeman DS, Maro GS, Han S, Banko MR, Gozani O, Brunet A. Members of the H3K4 trimethylation complex regulate lifespan in a germline-dependent manner in C. elegans. Nature 2010; 466(7304): 383-387

27. Berger SL. Transgenerational inheritance of longevity: epigenetic mysteries abound. Cell Metab 2012; 15(1): 6-7

28. Dias BG, Ressler KJ. Parental olfactory experience influences behavior and neural structure in subsequent generations. Nat Neurosci 2014; 17(1): 89-96

29. Benito E, Kerimoglu C, Ramachandran B, Pena-Centeno T, Jain G, Stilling RM, Islam MR, Capece V, Zhou Q, Edbauer D, Dean C, Fischer A. RNA-dependent intergenerational inheritance of enhanced synaptic plasticity after environmental enrichment. Cell Rep 2018; 23(2): 546-554

30. Gapp K, Soldado-Magraner S, Alvarez-Sánchez M, Bohacek J, Vernaz G, Shu H, Franklin TB, Wolfer D, Mansuy IM. Early life stress in fathers improves behavioural flexibility in their offspring. Nat Commun 2014; 5(1): 5466

31. Wu L, Lu Y, Jiao Y, Liu B, Li S, Li Y, Xing F, Chen D, Liu X, Zhao J, Xiong X, Gu Y, Lu J, Chen X, Li X. Paternal psychological stress reprograms hepatic gluconeogenesis in offspring. Cell Metab 2016; 23(4): 735-743

32. Schuster A, Skinner MK, Yan W. Ancestral vinclozolin exposure alters the epigenetic transgenerational inheritance of sperm small noncoding RNAs. Environ Epigenet 2016; 2(1): dvw001

33. Rompala GR, Mounier A, Wolfe CM, Lin Q, Lefterov I, Homanics GE. Heavy chronic intermittent ethanol exposure alters small noncoding RNAs in mouse sperm and epididymosomes. Front Genet 2018; 9: 32

34. Wagner KD, Wagner N, Ghanbarian H, Grandjean V, Gounon P, Cuzin F, Rassoulzadegan M. RNA induction and inheritance of epigenetic cardiac hypertrophy in the mouse. Dev Cell 2008; 14(6): 962-969

35. Grandjean V, Gounon P, Wagner N, Martin L, Wagner KD, Bernex F, Cuzin F, Rassoulzadegan M. The miR-124-Sox9 paramutation: RNA-mediated epigenetic control of embryonic and adult growth. Development 2009; 136(21): 3647-3655

36. Holoch D, Moazed D. RNA-mediated epigenetic regulation of gene expression. Nat Rev Genet 2015; 16(2): 71-84

37. Carone BR, Fauquier L, Habib N, Shea JM, Hart CE, Li R, Bock C, Li C, Gu H, Zamore PD, Meissner A, Weng Z, Hofmann HA, Friedman N, Rando OJ. Paternally induced transgenerational environmental reprogramming of metabolic gene expression in mammals. Cell 2010; 143(7): 1084-1096

38. Fullston T, Ohlsson Teague EM, Palmer NO, DeBlasio MJ, Mitchell M, Corbett M, Print CG, Owens JA, Lane M. Paternal obesity initiates metabolic disturbances in two generations of mice with incomplete penetrance to the F2 generation and alters the transcriptional profile of testis and sperm microRNA content. FASEB J 2013; 27(10): 4226-4243

39. Peng H, Shi J, Zhang Y, Zhang H, Liao S, Li W, Lei L, Han C, Ning L, Cao Y, Zhou Q, Chen Q, Duan E. A novel class of tRNA-derived small RNAs extremely enriched in mature mouse sperm. Cell Res 2012; 22(11): 1609-1612

40. Reilly JN, McLaughlin EA, Stanger SJ, Anderson AL, Hutcheon K, Church K, Mihalas BP, Tyagi S, Holt JE, Eamens AL, Nixon B. Characterisation of mouse epididymosomes reveals a complex profile of microRNAs and a potential mechanism for modification of the sperm epigenome. Sci Rep 2016; 6(1): 31794

41. Hutcheon K, McLaughlin EA, Stanger SJ, Bernstein IR, Dun MD, Eamens AL, Nixon B. Analysis of the small non-protein-coding RNA profile of mouse spermatozoa reveals specific enrichment of piRNAs within mature spermatozoa. RNA Biol 2017; 14(12): 1776-1790

42. Sullivan R. Epididymosomes: role of extracellular microvesicles in sperm maturation. Front Biosci (Schol Ed) 2016; 8(1): 106-114

43. Hua M, Liu W, Chen Y, Zhang F, Xu B, Liu S, Chen G, Shi H, Wu L. Identification of small non-coding RNAs as sperm quality biomarkers for in vitro fertilization. Cell Discov 2019; 5(1): 20

44. Zhang Y, Zhang X, Shi J, Tuorto F, Li X, Liu Y, Liebers R, Zhang L, Qu Y, Qian J, Pahima M, Liu Y, Yan M, Cao Z, Lei X, Cao Y, Peng H, Liu S, Wang Y, Zheng H, Woolsey R, Quilici D, Zhai Q, Li L, Zhou T, Yan W, Lyko F, Zhang Y, Zhou Q, Duan E, Chen Q. Dnmt2 mediates intergenerational transmission of paternally acquired metabolic disorders through sperm small non-coding RNAs. Nat Cell Biol 2018; 20(5): 535-540

45. Nätt D, Kugelberg U, Casas E, Nedstrand E, Zalavary S, Henriksson P, Nijm C, Jäderquist J, Sandborg J, Flinke E, Ramesh R, Örkenby L, Appelkvist F, Lingg T, Guzzi N, Bellodi C, Löf M, Vavouri T, Öst A. Human sperm displays rapid responses to diet. PLoS Biol 2019; 17(12): e3000559

46. Shi J, Zhang Y, Tan D, Zhang X, Yan M, Zhang Y, Franklin R, Shahbazi M, Mackinlay K, Liu S, Kuhle B, James ER, Zhang L, Qu Y, Zhai Q, Zhao W, Zhao L, Zhou C, Gu W, Murn J, Guo J, Carrell DT, Wang Y, Chen X, Cairns BR, Yang XL, Schimmel P, ZernickaGoetz M, Cheloufi S, Zhang Y, Zhou T, Chen Q. PANDORA-seq expands the repertoire of regulatory small RNAs by overcoming RNA modifications. Nat Cell Biol 2021; 23(4): 424-436

47. Kiani J, Grandjean V, Liebers R, Tuorto F, Ghanbarian H, Lyko F, Cuzin F, Rassoulzadegan M. RNA-mediated epigenetic heredity requires the cytosine methyltransferase Dnmt2. PLoS Genet 2013; 9 (5): e1003498

48. Sarker G, Sun W, Rosenkranz D, Pelczar P, Opitz L, Efthymiou V, Wolfrum C, Peleg-Raibstein D. Maternal overnutrition programs hedonic and metabolic phenotypes across generations through sperm tsRNAs. Proc Natl Acad Sci USA 2019; 116(21): 1054710556

49. Peleg-Raibstein D, Sarker G, Litwan K, Krämer SD, Ametamey SM, Schibli R, Wolfrum C. Enhanced sensitivity to drugs of abuse and palatable foods following maternal overnutrition. Transl Psychiatry 2016; 6(10): e911

50. Sarker G, Berrens R, von Arx J, Pelczar P, Reik W, Wolfrum C, Peleg-Raibstein D. Transgenerational transmission of hedonic behaviors and metabolic phenotypes induced by maternal overnutrition. Transl Psychiatry 2018; 8(1): 195

51. Radford EJ, Ito M, Shi H, Corish JA, Yamazawa K, Isganaitis E, Seisenberger S, Hore TA, Reik W, Erkek S, Peters AHFM, Patti ME, Ferguson-Smith AC. In utero undernourishment perturbs the adult sperm methylome and intergenerational metabolism. Science 
2014; 345(6198): 1255903

52. Shea JM, Serra RW, Carone BR, Shulha HP, Kucukural A, Ziller MJ, Vallaster MP, Gu H, Tapper AR, Gardner PD, Meissner A, Garber M, Rando OJ. Genetic and epigenetic variation, but not diet, shape the sperm methylome. Dev Cell 2015; 35(6): 750-758

53. Sendler E, Johnson GD, Mao S, Goodrich RJ, Diamond MP, Hauser R, Krawetz SA. Stability, delivery and functions of human sperm RNAs at fertilization. Nucleic Acids Res 2013; 41(7): 4104-4117

54. Kawano M, Kawaji H, Grandjean V, Kiani J, Rassoulzadegan M. Novel small noncoding RNAs in mouse spermatozoa, zygotes and early embryos. PLoS One 2012; 7(9): e44542

55. Krawetz SA, Kruger A, Lalancette C, Tagett R, Anton E, Draghici S, Diamond MP. A survey of small RNAs in human sperm. Hum Reprod 2011; 26(12): 3401-3412

56. Dietz DM, Laplant Q, Watts EL, Hodes GE, Russo SJ, Feng J, Oosting RS, Vialou V, Nestler EJ. Paternal transmission of stressinduced pathologies. Biol Psychiatry 2011; 70(5): 408-414

57. Rodgers AB, Morgan CP, Bronson SL, Revello S, Bale TL. Paternal stress exposure alters sperm microRNA content and reprograms offspring HPA stress axis regulation. J Neurosci 2013; 33(21): 9003-9012

58. Bohacek J, Farinelli M, Mirante O, Steiner G, Gapp K, Coiret G, Ebeling M, Durán-Pacheco G, Iniguez AL, Manuella F, Moreau JL, Mansuy IM. Pathological brain plasticity and cognition in the offspring of males subjected to postnatal traumatic stress. Mol Psychiatry 2015; 20(5): 621-631

59. Gapp K, Bohacek J, Grossmann J, Brunner AM, Manuella F, Nanni P, Mansuy IM. Potential of environmental enrichment to prevent transgenerational effects of paternal trauma. Neuropsychopharmacology 2016; 41(11): 2749-2758

60. McGreevy KR, Tezanos P, Ferreiro-Villar I, Pallé A, MorenoSerrano M, Esteve-Codina A, Lamas-Toranzo I, Bermejo-Álvarez P, Fernández-Punzano J, Martín-Montalvo A, Montalbán R, Ferrón
SR, Radford EJ, Fontán-Lozano Á, Trejo JL. Intergenerational transmission of the positive effects of physical exercise on brain and cognition. Proc Natl Acad Sci USA 2019; 116(20): 1010310112

61. Wang Y, Chen ZP, Hu H, Lei J, Zhou Z, Yao B, Chen L, Liang G, Zhan S, Zhu X, Jin F, Ma R, Zhang J, Liang H, Xing M, Chen XR, Zhang CY, Zhu JN, Chen X. Sperm microRNAs confer depression susceptibility to offspring. Sci Adv 2021; 7(7): eabd7605

62. Gapp K, van Steenwyk G, Germain PL, Matsushima W, Rudolph KLM, Manuella F, Roszkowski M, Vernaz G, Ghosh T, Pelczar P, Mansuy IM, Miska EA. Alterations in sperm long RNA contribute to the epigenetic inheritance of the effects of postnatal trauma. Mol Psychiatry 2020; 25(9): 2162-2174

63. Chan JC, Morgan CP, Adrian Leu N, Shetty A, Cisse YM, Nugent $\mathrm{BM}$, Morrison $\mathrm{KE}$, Jašarević E, Huang $\mathrm{W}$, Kanyuch N, Rodgers AB, Bhanu NV, Berger DS, Garcia BA, Ament S, Kane M, Neill Epperson C, Bale TL. Reproductive tract extracellular vesicles are sufficient to transmit intergenerational stress and program neurodevelopment. Nat Commun 2020; 11(1): 1499

64. Liu WM, Pang RT, Chiu PC, Wong BP, Lao K, Lee KF, Yeung WS. Sperm-borne microRNA-34c is required for the first cleavage division in mouse. Proc Natl Acad Sci USA 2012; 109(2): 490-494

65. Hong Y, Wang C, Fu Z, Liang H, Zhang S, Lu M, Sun W, Ye C, Zhang CY, Zen K, Shi L, Zhang C, Chen X. Systematic characterization of seminal plasma piRNAs as molecular biomarkers for male infertility. Sci Rep 2016; 6(1): 24229

66. Roberts TC. The microRNA Biology of the mammalian nucleus. Mol Ther Nucleic Acids 2014; 3: e188

67. Sinkkonen L, Hugenschmidt T, Berninger P, Gaidatzis D, Mohn F, Artus-Revel CG, Zavolan M, Svoboda P, Filipowicz W. MicroRNAs control de novo DNA methylation through regulation of transcriptional repressors in mouse embryonic stem cells. Nat Struct Mol Biol 2008; 15(3): 259-267 